\title{
Púchkin como o Deus da literatura russa e Dostoiévski como seu Profeta: uma análise do discurso proferido por Dostoiévski no Festival Púchkin
}

\section{Giuliana Teixeira de Almeida ${ }^{1}$}

Mesmo para alguém afeito a incendiar plateias, o Festival Púchkin foi para Fiódor Dostoiévski um acontecimento sem precedentes no terreno da aclamação pública. O grande evento aconteceu em Moscou no ano de 1880 em decorrência da inauguração nesta mesma cidade de um monumento (uma estátua) em homenagem ao poeta. Os nomes mais destacados das letras russas, sendo Dostoiévski um deles, foram convocados para discursarem sobre a importância de Púchkin. Em carta endereçada à mulher escrita no calor dos acontecimentos, o grande romancista afirma: "Não, Ánia, não, você nunca vai conceber e imaginar o efeito que ele [o discurso] produziu! O que são meus sucessos em Petersburgo! Nada, zero, quando comparados com este!" (Frank, 2007, 651). Outros relatos legados pelos contemporâneos acerca do Festival nos permitem assegurar que Dostoiévski não exagerou em nada o alcance do seu triunfo.

Lida a última palavra do discurso de Dostoiévski sobre Púchkin, irrompeu no auditório uma salva de aplausos frenéticos acompanhados das mais inesperadas reações, muitas delas beirando a histeria. Os pormenores dessa grande convulsão são descritas pelo próprio romancista e reproduzidas por Joseph Frank no último volume da sua monumental biografia Dostoiévski - O Manto do Profeta (1871-1881):

(...) No entanto, quando falei, no final, da unidade universal do povo, a sala entrou como que em histeria. Quando terminei - não vou lhe falar do ruído ensurdecedor, do alarido de entusiasmo, estranhos na plateia choravam, soluçavam, abraçavam-se uns aos outros, e prometiam uns aos outros ser melhores, não odiar uns aos outros a partir daquele momento, mas amarem-se entre si. A sessão entrou em desordem, todo o

\footnotetext{
${ }^{1}$ Bacharel em História (Universidade de São Paulo) e mestranda no programa de Cultura e Literatura Russa do departamento de Letras Orientais da Universidade de São Paulo. Projeto de Pesquisa "Pelo Prisma Biográfico: Joseph Frank e Dostoiévski" financiado pela Fundação de Amparo à Pesquisa de São Paulo - FAPESP. Contato: giualmeida@yahoo.com.br.
} 
mundo corria para o palco para me ver, damas bem-nascidas, estudantes mulheres, secretários de Estado, estudantes homens - todos eles me abraçavam e me beijavam. Todos os membros da nossa sociedade [ a SALR], que estavam no palco me abraçavam e me beijavam. Todos eles, literalmente todos eles choravam de emoção. As chamadas ao palco continuaram por meia hora; as pessoas agitavam lenços; de repente, por exemplo, dois homens idosos que eu não conhecia me pararam: "Fomos inimigos um do outro por vinte anos, não falávamos um com o outro, mas agora nos abraçamos e nos reconciliamos. Foi o senhor que nos reconciliou, o senhor, nosso santo, o senhor, nosso profeta!" "Profeta! Profeta!" as pessoas na multidão gritavam.

Turguéniev, de quem falei bem em meu discurso, correu para me abraçar com lágrimas nos olhos. Ánenkov levantou-se para apertar-me a mão e beijar meu ombro: "O senhor é um gênio, o senhor é mais do que um gênio!", ambos me disseram. Aksákov subiu ao palco e declarou à plateia que meu discurso não era apenas um discurso, mas um acontecimento histórico!(...) A sessão foi interrompida. Corri para os bastidores para fugir, mas todos que estavam no salão estouraram lá, e sobretudo as mulheres. Elas beijavam-me as mãos, me atormentavam. Alguns estudantes chegaram correndo. Um deles, em lágrimas caiu ao solo à minha frente em convulsões e perdeu a consciência. Uma vitória completa, absolutamente completa! (Frank, 2007, 651)

Segundo Joseph Frank, todos os acontecimentos descritos nesse relato podem ser confirmados através do cruzamento das fontes que restaram sobre o evento. A única ressalva diz respeito ao episódio dos inimigos que se reconciliaram que não consta em nenhum outro testemunho.

Não se deve perder de vista que o Festival foi organizado pela intelectualidade russa e que eventos como esse, apesar do enfoque literário, traziam consigo uma forte conotação política característica do papel que a literatura ocupava na Rússia Czarista: esta era o centro irradiador dos debates políticos, sociais e filosóficos, que não podiam ser travados diretamente, mas somente por meio do subterfúgio literário. A exaltação que a ousadia dessa empresa causou entre os envolvidos foi agravada pelo clima de tensão que rondava o país em decorrência de uma série de atentados, até o momento mal sucedidos, promovidos contra a vida do Czar Alexandre II pelos grupos revolucionários. Dostoiévski soube valer-se desse clima tenso e, em uma jogada de mestre, ofereceu a esse público tudo aquilo que ele esperava ouvir em tempos de incerteza e de 
dilaceramento do tecido social: uma mensagem de união e a transformação de Púchkin no porta voz dessa mensagem.

Com a sua participação o romancista ofuscou todos os seus colegas de letras, inclusive Turguêniev, seu desafeto de longa data, que analisou a importância de Púchkin em um discurso cerebral, equilibrado e com conclusões sóbrias e nada messiânicas acerca do legado do grande poeta. Além disso, o escritor "had hesitate to promove Pushkin into the elite of world-class geniuses" (Levitt, 1989, 130), atitude que destoou do clima exaltado do evento. Dostoiévski, ao contrário de Turguêniev, não só ergueu Púchkin ao patamar dos grandes gênios, como também o elevou acima de Shakespeare, Goethe, Homer e Schiller. Alguns estudiosos do assunto avaliaram esse confronto entre Turguêniev e Dostoiévski pelo prisma da questão basilar da cultura russa nesse período histórico que opunha os Ocidentalistas, aqueles que almejavam para a Rússia um desenvolvimento nos moldes da Europa Ocidental, aos Eslavófilos, aqueles que valorizavam as especificidades do desenvolvimento histórico, social e político da Rússia e consideravam de pouca serventia para o país o modelo oferecido pelas sociedades europeias. Seguindo essa perspectiva, no Festival Púchkin Turguêniev despontaria como o representante do campo Ocidentalista enquanto Dostoiévski como principal nome do campo Eslavófilo. Por conseguinte, a vitória teria ficado com Dostoiévski e o campo dos Eslavófilos.

É interessante atentar para o fato de que o discurso que foi aplaudido em uníssono quando lido na ocasião do Festival foi duramente criticado após a sua publicação em um importante periódico da época. A controvérsia foi tamanha que, segundo Marcus C. Levitt, “For six months after the Pushkin Celebration, Dostoevsky's speech (...) was reprinted over a dozen times and reviewed in at least sixty-five articles in over forty newspapers and journals" (Levitt, 1989, 138). A versão impressa desagradou a muitos dos contemporâneos do escritor, inclusive a alguns que haviam presenciado a leitura de Dostoiévski e que naquela ocasião encararam o discurso como a palavra final sobre a importância da obra de Púchkin para o povo russo. Um dos que discordaram do conteúdo do discurso foi o próprio Turguêniev, que apesar das suas desavenças com Dostoiévski havia saudado o romancista após a sua leitura (e durante a leitura, pois o escritor assoprou um beijo para Dostoiévski quando foi mencionado por esse último nesse mesmo discurso). As criticas de Turguêniev também puderam ser encontradas em outras análises do texto de Dostoiévski sobre Púchkin, não podendo ser 
tomadas como fruto da inveja ou de qualquer outro sentimento pessoal em relação ao colega de ofício.

Portanto, quando os ânimos exaltados do Festival se esfriaram e com o discurso em mãos, os oponentes de Dostoiévski procuraram uma explicação para a razão daquele enigmático sucesso, o mesmo que os historiadores e estudiosos do assunto tem buscado fazer até os dias de hoje. Alguns dos especialistas encontraram uma possível explicação na relação que Dostoiévski estabeleceu com os seus leitores nos anos finais da sua vida. De acordo com esse ponto de vista, a crescente admiração dos leitores pela figura do escritor culminou em cega veneração na ocasião do Festival. Para Marcus Levitt, tamanha popularidade deveu-se ao último romance do escritor, Os Irmãos Karamázov. Já Raffaella Vassena sustenta que a relação de cumplicidade e adoração foi construída por meio de $O$ Diário de um Escritor, uma publicação criada por Dostoiévski na qual este discutia os acontecimentos da ordem do dia e expressava as suas ideias políticas e literárias com toda a liberdade. O Diário de um Escritor, que surgiu como uma coluna no jornal o Cidadão (1873) e que mais tarde se tornou um periódico independente de total responsabilidade de Dostoiévski (1876-77/1881) foi, segundo o biógrafo Joseph Frank, a publicação mais lida entre todas aquelas semelhantes que apareceram em seu período de vida.

A popularidade de Dostoiévski oferece uma explicação satisfatória, porém parcial para o sucesso da fala do escritor sobre Púchkin, pois como alguns desses mesmos estudiosos admitiram a chave para a compreensão do estrondoso sucesso está na forma e no conteúdo do discurso. Quanto à forma, Levitt defende que "Whatever we make of Dostoevsky's ideas, his Pushkin Speech remains a brilliant piece of rhetoric designed to disarm, defeat, and win over his audience". Já o conteúdo do discurso é sem sombra de dúvidas o aspecto mais impenetrável para os estudiosos e leitores dos nossos dias. Principalmente quando este leitor está familiarizado apenas com a produção literária do escritor e pouco ou nada sabe sobre as ideias políticas que o grande romancista russo cultivou em vida. Unanimidade literária, um dos maiores escritores da literatura universal é também um pensador controverso, capaz de deixar boquiabertos os seus mais incondicionais admiradores com o conservadorismo e o preconceito de algumas das suas posições políticas expressas principalmente por meio da sua atuação na imprensa russa da época. Alguns exemplos dessas posições desconcertantes podem ser retirados das páginas do já mencionado O Diário de um Escritor. 
As maiores vítimas do polemista Dostoiévski são sem sombra de dúvidas os seus dedicados biógrafos. Muitos deles realizaram a sua obra equilibrando-se entre uma veneração incontida e uma perplexidade crescente diante dos textos jornalísticos do escritor, muitas vezes repletos de ideias antissemitas, xenófobas e imperialistas. Joseph Frank é um excelente exemplo de um biógrafo encantado com o Dostoiévski escritor e desconcertado com o Dostoiévski polemista. No prefácio do quinto volume da biografia Dostoiévski, o biografo chega a afirmar que as pretensas (grifo meu) ideias políticas de Dostoiévski "pareciam tão excêntricas que dificilmente alguém as levaria a sério. Na verdade, é minha opinião que se quisermos fazer-lhe justiça como romancista, devemos esquecê-las" (Frank, 2007, 14). Nesse último volume, esse mesmo apelo vem à tona diversas vezes, por exemplo, quando Frank se debruça sobre o último texto que foi redigido pelo romancista no seu Diário (uma glorificação da aventura malsucedida da Rússia na sua tentativa de conquistar o oásis de Geok Tape e a defesa de uma "missão civilizatória" na Ásia) e conclui que:

Infelizmente, o que Dostoiévski tem a dizer no caso não figura entre suas elocuções mais impressionantes e atraentes. Mas dever-se-ia ler suas últimas palavras impressas sempre com a mente concentrada em suas grandes realizações no campo da criação - as obras- primas - que superam em importância e escondem suas ilusões e autoenganos sociopolíticos (Frank, 2007, 899-900)

Por conseguinte, a proposta que o biógrafo faz ao leitor é sintomática do receio de que essa faceta da complexa personalidade do escritor russo macule a sua gloriosa imagem de gigante das letras.

Não podendo passar ao largo dessa questão, Frank dedicou muitas páginas da sua biografia aos textos nos quais essas ideias políticas encontram-se expressas. O biógrafo norte-americano detectou uma maior complexidade no pensamento de Dostoiévski, na contramão da maioria dos biógrafos anteriores, e não retratou o escritor na sua biografia como um firme e implacável conservador político. Para Frank, no pensamento de Dostoiévski misturava-se "uma defesa das estruturas sociais mais reacionárias em nome dos princípios mais liberais" (Frank, 2007, 893), portanto o apoio irrestrito ao Czarismo e à Ortodoxia convivia com o anseio por mudanças estruturais, porém por uma via pacífica e não revolucionária. Mas essa premissa que levou Frank a enxergar uma possível "divisão interna dentro dele mesmo" (Frank, 2007, 393) no tocante as convicções mais espinhosas como, por exemplo, o antissemitismo, não 
impediu que em algumas passagens um desapontamento sincero escapasse da sua pena de biógrafo. No caso do antissemitismo, por exemplo, Frank rotula de "repulsivo" o ódio incontido e injustificável que o escritor russo nutria pelos judeus, contra quem no Diário "fez as acusações mais terríveis, chamando-os de exploradores impiedosos da miséria alheia, induzidos pela sede insaciável do ganho, e culpando-os de desenvolverem sua influência internacional contra os interesses do Estado russo" (Frank, 2007, 381). Já no caso do nacionalismo xenófobo e do imperialismo tacanho de Dostoiévski, desdobramentos do seu amor pela pátria, Frank também lamenta os excessos do escritor que podem ser localizados, por exemplo, no seu último texto (já mencionado) sobre as pretensões imperialistas da Rússia na Ásia, ou na sua defesa da guerra Russo-Turca (1877-78) e a justificação em elevados princípios morais e religiosos do envolvimento do seu país no conflito balcânico. Para Frank, "as elucubrações de Dostoiévski sobre a Questão Balcânica estão entre suas páginas mais entediantes e deploráveis, e apenas repetem os mesmos autopanegíricos nacionalistas em contextos diferentes" (Frank, 2007, 354).

Entretanto, quanto à obsessão de Dostoiévski pelo destino do seu país, Frank tenta procurar nas páginas do escritor resquícios de uma possível consciência da parte deste último da irrealidade de certas convicções acerca da grandeza e retidão moral e espiritual da Rússia. Ele localiza esses resquícios nos textos que evocavam com alguma regularidade a figura literária de Don Quixote, quem inspira Dostoiévski a indagar aos seus leitores se estes nunca acalentaram um sonho, uma ideia, que poderia perfeitamente se tratar de uma mentira e que para se evitar que assim o fosse não se apressaram em inventar um novo sonho, uma nova mentira, apenas para resolver de uma vez por todas a dúvida anterior. Para Frank,

Se isso pode ser verdade com relação aos leitores de Dostoiévski, pode sê-lo igualmente para ele próprio. É impossível deixar de indagar se aqui, nessas reflexões tristemente melancólicas, Dostoiévski também não estava dando voz a alguma incerteza interior sobre suas mais caras convicções relativas ao povo russo e ao glorioso papel que ele deveria representar, no futuro, na história mundial. Não teria ele, que entendia tão bem a capacidade do homem de auto-iludir-se, ter sentido também algumas vezes que suas grandiosas previsões eram um meio de resgatar- 
se do desespero quando contemplava sua Dulcinéia russa? (Frank, 2007, $358)$.

Apesar dessa bela construção argumentativa do biografo, podemos duvidar da propriedade da sua conclusão. É pouco provável que o escritor de fato desconfiasse da sua convicção mais arraigada, cultivada por toda a vida e, no final dela, emprestada à Púchkin no seu famoso discurso de 1880 proferido durante as homenagens ao poeta em Moscou. No emaranhado das ideias nacionalistas defendidas por Dostoiévski jamais sofreu qualquer abalo ao longo da trajetória do escritor a visão positiva e esperançosa do futuro da sociedade russa em oposição à visão pessimista do destino da Europa Ocidental.

Para Dostoiévski, a desintegração social da Europa havia alcançado um estágio tão dramático que apenas por meio de violência ou de uma guerra de classes impiedosa se resolveria a grande questão social, ao passo que na Rússia a solução seria pacífica e fundamentada no amor cristão (o exemplo cabal era a libertação dos servos que havia sido feita de maneira pacífica pela vontade do Czar). Isso porque, no seu entendimento, a classe dirigente russa agia orientada pelos ideais cristãos do povo, e por essa razão a sociedade aproximava-se cada vez mais de um consenso acerca da solução dos problemas sociais. Assim, para Dostoiévski era "possível que o reino do pensamento e da luz se realize aqui, em nossa Rússia, até mais cedo talvez do que em qualquer outro lugar”(Frank, 2007, 348). Ao contrário da Europa Ocidental, a Rússia desconhecia o egoísmo e o culto ao indivíduo e a essa inclinação fraterna somar-se-ia, na síntese nacional, a disposição universalista do homem russo e o seu dom de incorporar as características dos outros povos. Assim, o Reino de Deus na terra seria alcançado na Rússia pioneiramente como um reflexo da fraternidade e do desejo de união inerente ao povo russo.

Como já mencionado, as ideias messiânicas de Dostoiévski sobre o destino do povo russo foram projetadas por ele no significado profundo da obra de Púchkin e explanadas no discurso em homenagem ao poeta. Mais do que isso, "For Dostoevsky, Pushkin represents the only demonstrable proof of his ideas" (Levitt, 1989, 130). Assim, a observação de Gógol de que Púchkin teria sido um fenômeno extraordinário e único do espírito russo, Dostoiévski completa: e profético. Isso porque este, na sua 
visão, foi o primeiro a identificar a vocação universalista dos russos e, por conseguinte, a sua missão nacional.

Ao contrário dos grandes poetas europeus, que jamais obtiveram sucesso na representação de outros povos, Púchkin foi o único dos poetas mundiais com uma sensibilidade universal genuína, portanto capaz de, em suas obras, converter-se em representante de outras nações que não a sua. Para Dostoiévski, essa característica é também um fenômeno profético, pois a grande força dos russos enquanto povo advém dessa propensão à universalidade. Dessa forma, Púchkin foi o primeiro a apontar a predestinação do homem russo e a expressá-la na sua criação artística: ser um homem universal, reconciliar definitivamente as contradições europeias e pronunciar a palavra final da harmonia geral, da definitiva concórdia fraternal de todos os povos de acordo com os ensinamentos de Cristo. O poeta, na visão de Dostoiévski, indicou o caminho a ser seguido pelos seus continuadores na literatura e pelo povo russo, como um todo, na sua missão histórica.

Na festiva ocasião em que a Rússia letrada homenageou Púchkin, ao tentar deslindar o segredo que passou a envolver a obra do poeta após a sua morte prematura, Dostoiévski convenceu de tal maneira a todos os presentes que, conforme o relato de um jovem estudante que testemunhou o ocorrido, quando o grande romancista terminou o seu discurso das últimas fileiras do auditório soou um grito histérico: "Você o descobriu [o segredo de Púchkin], que foi ecoado por diversas vozes femininas em coro" (Frank, 2007, 661). Dessa maneira, ao revelar o fenômeno profético que foi Púchkin, Dostoiévski também passou a ser associado à figura do profeta. Nas palavras de Frank, "desde o Festival de Púchkin essa figura [do profeta] identificava-se cada vez mais com ele [Dostoiévski]" (Frank, 2007, 701). É importante ressaltar que na sessão final do festival coube a Dostoiévski a declamação do poema O Profeta de Púchkin, leitura que coroou a exaltação quase mística da noite. Até a sua morte, Dostoiévski faria muitas outras leituras públicas desse poema, um dos seus favoritos segundo Frank.

Traços essenciais da cultura russa elucidam a associação desses dois grandes nomes da literatura à figura do profeta, assim como a recorrência desse tema (poetaprofeta) nessa tradição literária. A herança Bizantina é determinante na formação do Estado russo. A escrita surgiu na Rússia através do Cristianismo Ortodoxo, e essa interpenetração conferiu à palavra escrita um lastro sagrado. É por essa razão que na 
cultura russa a forma de arte mais importante é a literatura (sendo a poesia o gênero principal) e o papel de maior destaque é ocupado nessa sociedade pelos homens de letras (escritores em geral e principalmente poetas). Os escritores são vistos como instrumentos da revelação da verdade de Deus (Ístina), e muitos deles tenderam a considerarem-se de fato portadores da revelação divina. Essa ideia aparece na primeira obra que apresentou ao Ocidente uma história da literatura russa: $O$ Romance Russo, de Melchior de Vogüé. No capítulo destinado à apreciação crítica da obra de Turguêniev, o autor francês ressalta que "O escritor passa a ser o guia de sua raça, o ordenador de uma infinidade de ideias confusas, e ainda um pouco o criador de sua língua; o poeta no sentido antigo e total da palavra - vates, poeta, profeta" (Vogüé, 142).

Ao analisarmos o discurso de Dostoiévski nos dias de hoje, de maneira distanciada e objetiva, sem termos vivenciado o seu pronunciamento público e sem carregarmos a herança cultural russa, tendemos a concluir que há um exagero da parte do romancista na sua leitura do significado da obra do poeta à luz das suas convicções acerca da missão universal do povo russo. No entanto, se do ponto de vista do desvendar do segredo de Púchkin não conseguimos relacionar Dostoiévski à figura do profeta, de outro ângulo essa associação tende a nos parecer não tão completamente descabida. Púchkin escreveu: "Olho aberto, de pé, profeta e, com teu verbo, cruzando as terras, os oceanos, cheio de afã soberbo, inflama os corações humanos!" (Púchkin, 2006, 240-241) [grifo meu] e Dostoiévski, à maneira do profeta, com sua grande obra incendiou (e continua a incendiar) os corações dos homens.

\section{Referências bibliográficas:}

Dostoievski, Fédor. "Pushkin”. In: Novikova, Olga (org.). Rusia y Occidente (Antología de textos). Editora: Tecnos.

Frank, Joseph. Dostoiévski: O Manto do Profeta, 1871-1881. São Paulo: Editora da Universidade de São Paulo, 2007.

Levitt, Marcus C. Russian Literary Politics and the Pushkin Celebration of 1880. Columbia University/Studies of Harriman Institute: Cornell University Press, 1989.

Púchkin, Aleksandr. A Dama de Espadas: Prosa e Poemas. São Paulo: Editora 34, 2006. 
Vassena, Raffaella. Reawakening National Identity: Dostoevskii's Diary of a Writer and Its Impact on Russian Society. Bern: Peter Lang AG, International Academic Publishers, 2007.

Vogüé, Melchior de. O Romance Russo. Rio de Janeiro: Editora A Noite (Ano de publicação desconhecido). 